\title{
A PROBLEMÁTICA DA INFÂNCIA EM DOIS CONTOS DE MOACYR SCLIAR: ESTRANHEZA, HORROR E VIOLÊNCIA
}

\author{
Suzana Yolanda L. Machado Cánovas ${ }^{1}$ \\ Kelio Junior Santana Borges ${ }^{2}$
}

Resumo: Este estudo tem o objetivo de estudar a estranheza causada pela morte que, em dois contos do escritor brasileiro Moacyr Scliar, é associada ao horror e à violência ligada à criança. Nossa análise se deterá nas narrativas "Trem fantasma" e "O dia em que matamos James Cagney", ambas publicadas na coletânea $O$ carnaval dos animais, publicada originalmente em 1968.

Palavras-chave: Moacyr Scliar. Contos brasileiros. Narrativa fantástica. Infância.

Moacyr Scliar (1937-2011), escritor e médico sanitarista, era filho de imigrantes judeus que se estabeleceram na cidade de Porto Alegre (RS). Foi autor de narrativas que se caracterizam pela presença do insólito e inaugurou uma nova vertente na ficção brasileira, inserindo em suas obras a problemática judaica. Ao longo de sua trajetória literária, ele não abandonou o tema do judeu e da diáspora. O escritor publicou romances, novelas, contos, ficção infanto-juvenil, crônicas e ensaios de forma ininterrupta. Recebeu muitos prêmios literários e teve seus textos traduzidos para catorze idiomas. Algumas de suas obras foram adaptadas para o cinema, a televisão e o teatro.

Tendo escrito mais de oitenta títulos, perpassando diferentes gêneros, boa parte dessa produção foi dedicada ao público infantil e juvenil; foram perto de vinte títulos voltados ao público jovem, dentre os quais destacamos: Cavalos e obeliscos (1981), A festa no castelo (1987), No caminho dos sonhos (1988), O tio que flutuava (1988), Introdução à prática amorosa (1988), Os cavalos da república (1989), Pra você eu conto (1991), Um país chamado infância (1993), Minha mãe não dorme enquanto eu não chegar (1994), Uma história só pra mim (1994), O sonho no caroço do abacate (1995), Rio Grande farroupilha (1995), Câmara na mão, O Guarani no coração (1998), A colina dos suspiros (1999), O mistério da casa verde (2000),

\footnotetext{
${ }^{1}$ Doutora pela Universidade Federal do Rio Grande do Sul - UFRGS. Pesquisadora do Programa de Pós-Graduação em Letras e Linguística, da Universidade Federal de Goiás - UFG. Goiânia, GO, Brasil.

2 Doutorando do programa de Pós-Graduação em Letras e Linguística da Universidade Federal de Goiás, pesquisador vinculado a linha de pesquisa Literatura, história e sociedade, a partir da qual aborda a obra da escritora Lygia Fagundes Telles. Membro do projeto de pesquisa "Rede de Estudos de Língua Portuguesa ao Redor do Mundo - RELPMUND (CNPq) e Bolsista CAPES Doutorado-Sanduíche na Università degli Studi Roma Tre - Itália.
} 
Ataque ao comando P. Q (2001). Moacyr Scliar foi um leitor voraz quando criança e defendia o caráter transformador da literatura na vida de uma pessoa que, desde cedo, começa a ler; por essa razão, o escritor assumiu o compromisso com a formação do leitor. Sua literatura infantojuvenil tem como marca uma linguagem clara, de fácil acesso, constituindo-se em uma via de mão dupla, facilitando a comunicação de seus narradores com a criança e o adolescente, assim como possibilita a entrada imediata do leitor nesse universo imaginário tão rico criado por Moacyr Scliar.

Além dessa importante e volumosa produção voltada para os jovens, Moacyr Scliar, em alguns textos, tangenciou a fase infantil buscando nela a origem de certas marcas psicológicas deixadas em suas personagens adultas. Vale dizer também o autor levava para sua produção adulta discussões ou imagens próprias da infância, tangenciando perspectivas dessa fase da vida, algumas vezes, representando, por meio disso, o diálogo entre diferentes gerações, como acontece, por exemplo, em sua última obra Eu vos abraço milhões (2010), em que Valdo, o avô, descreve sua vida para o neto, deixando-a registrada em forma de romance autobiográfico.

Neste estudo, nos debruçaremos sobre dois textos pertencentes ao livro de estreia do escritor. Analisaremos a estranheza causada pela morte, associada ao horror e à violência ligada à infância nos contos "Trem fantasma" e "O dia em que matamos James Cagney". Essas narrativas constam de $O$ carnaval dos animais ${ }^{3}$, que recebeu o Prêmio da Academia Mineira de Letras.

Vivendo no extremo sul de um país da América Latina, Scliar evidenciou, em sua produção literária, a situação de estranheza do judeu num mundo que the é adverso. O autor deu um curioso depoimento sobre o olho do judeu, estigmatizado como estrangeiro em qualquer parte da Terra em que habite:

Mas ele espia e expia. E aí - no olhar - está o primeiro poder do estranho. Ele vê coisas que os outros não veem. Olho arguto, olho mágico, enxerga poros nas superfícies lisas, minúsculas fissuras nos revestimentos. $O$

\footnotetext{
${ }^{3}$ O livro foi publicado inicialmente em 1968. Em 1976, saiu a $2^{2}$ edição revista e aumentada. O autor, conforme seu próprio depoimento, não se limitou a modificar os contos publicados em 1968, mas acrescentou novas narrativas em uma segunda parte, que ele denominou "Outras Histórias". Esse é o texto que tem sido reeditado a partir daí.
} 
estranho, até então frio e vazio como um ventre de larva, é agora um olho enigmático, brilhante como uma brasa na escuridão 4 .

Nos contos que constituem o corpus deste trabalho, a estranheza que the é peculiar está ligada às contingências inerentes à própria condição humana, sujeita à finitude e à morte, e à inserção do homem na sociedade burguesa e na violência do capitalismo exacerbado.

Para um estudo das narrativas, tomamos alguns pressupostos teóricos de Tzvetan Todorov (1975), ao enunciar os conceitos de fantástico, maravilhoso e estranho. No universo ficcional, diante da ocorrência de um fato que não pode ser explicado pelas leis que regem a natureza, aquele que o percebe, deve optar por uma de duas soluções possíveis: ou se trata de uma ilusão dos sentidos, de um produto da imaginação e, nesse caso, as leis do mundo continuam a ser o que sempre foram, ou o acontecimento realmente ocorreu, é parte integrante da realidade, mas ela passou a ser regida por leis desconhecidas para nós.

Segundo o autor, o fantástico é a hesitação ${ }^{5}$ de um ser que só conhece as leis naturais face a um acontecimento aparentemente sobrenatural. Ao escolher uma ou outra resposta, ele deixa o fantástico para entrar num gênero vizinho - o estranho ou o maravilhoso. O estranho é a presença, numa narrativa, de eventos que parecem sobrenaturais, mas que, no final, recebem uma explicação racional (sonho, alucinação, loucura). No gênero maravilhoso, as histórias terminam por uma aceitação do sobrenatural, já que os fatos não podem ser explicados pelas leis da natureza, tais como são conhecidas.

Todavia, existem narrativas em que o leitor jamais se interroga sobre a natureza dos eventos, sabendo perfeitamente que não deve tomá-los ao pé da letra, mas num outro sentido, que se chama alegórico. Segundo Todorov, a alegoria implica na existência de dois sentidos para as mesmas palavras. Além disso, esse duplo sentido é indicado na obra de maneira explícita, não dependendo, pois, da interpretação de um leitor qualquer, caso contrário, todas as obras seriam

\footnotetext{
${ }^{4}$ Depoimentos orais

${ }^{5}$ A definição de Todorov de fantástico como hesitação, que depende, portanto, da reação do leitor, ainda que esclareça que se trata de um leitor implícito, tem suscitado críticas de estudiosos no assunto, que não cabem nos limites deste trabalho
}

Revista de Letras JUÇARA, Caxias - Maranhão, v. 03, n. 01, p. 278 - 287, ago. 2019 | 280 
alegóricas, visto que estão abertas às múltiplas interpretações do leitor. No caso da alegoria, da mesma forma que na poesia, não há mais lugar para o fantástico.

Como informa João Adolfo Hansen (1986, p.01), a palavra "alegoria", vem do grego (allós = outro; agourein = falar) e, dessa forma, diz $b$ para significar $a$. Para defini-la, o autor recorre a Lausberg, que afirma que a "alegoria é a metáfora continuada como tropo de pensamento, e consiste na substituição do pensamento em causa por outro pensamento, que está ligado, numa relação de semelhança, a esse mesmo pensamento"(HANSEN, 1986, p.01).

Voltamo-nos agora para a alegoria presente em "Trem fantasma", narrativa em que Matias, uma criança de nove anos, sofria de leucemia, e estava à beira da morte. Como seu maior desejo era passear de Trem Fantasma, e não tinha condições de ir ao parque, a mãe pediu ajuda a um menino de dez anos, que é o narrador do conto, para ajudá-la a improvisar o espetáculo em sua própria casa.

Nesse conto, a questão judaica aparece apenas sugerida no nome da criança doente - Matias ("dom de Jeová ou Deus"), que é de origem hebraica. Não há, no texto, elementos sobrenaturais, pois o que existe é a improvisação de uma encenação macabra. O espetáculo é uma alegoria, pois apresenta uma sequência de cenas que, sem ter seu sentido literal (sentido próprio) obscurecido, requer que se realize uma outra leitura - a da morte iminente que assola o menino e sua família.

Para explicitar o que ocorre no texto, voltamos a Todorov, quando menciona uma afirmativa de Quintiliano - "Uma metáfora contínua se desenvolve em alegoria" - para, a seguir, acrescentar: "Uma metáfora isolada indica apenas uma maneira figurada de falar; mas se a metáfora é contínua, seguida, revela a intenção segura de falar de outra coisa além do objeto primeiro do enunciado" (TODOROV, 1975, p.70).

No texto estudado, fala-se inicialmente do trem fantasma, a seguir, como veremos abaixo, surgem as figuras da mãe vestida de bruxa, do pai enforcado, do irmão como esqueleto e das irmãs apunhaladas, que juntos, fornecem uma alegoria da morte.

A residência que constitui o cenário para o conto está situada num bairro tradicional da cidade de Porto Alegre, "Moinhos de Vento", que tem uma existência efetiva na realidade empírica, e é trazido para o mundo da ficção. Ali ainda existem 
antigos casarões, de famílias tradicionais e abastadas, mas hoje está invadido pelo comércio e especulação imobiliária.

Numa atmosfera gótica, nessa narrativa do século $X X$, os castelos arruinados são substituídos pelo antigo casarão lúgubre, no qual estão presentes os componentes do mórbido e do macabro. Assim, a ação transcorre num ambiente fechado, que transmite uma sensação de frio enclausuramento, numa casa silenciosa, com o minuano - um vento gelado que sopra no sul, no inverno assobiando lá fora entre as árvores.

A presença da casa remete-nos para o conceito de Gaston Bachelard de topoanálise, que é definida como "o estudo psicológico sistemático dos locais de nossa vida íntima" (BACHELARD, 1993, p.28). Contrariamente à premissa de metafísicos de que o ser humano é "atirado ao mundo", Bachelard salienta a importância da etapa inicial do espaço do bem-estar, do ser protegido no reduto primeiro do aconchego contra a hostilidade do mundo e dos homens. O autor acrescenta que "a casa é nosso canto do mundo. Ela é, como se diz amiúde, o nosso primeiro universo. É um verdadeiro cosmos" (BACHELARD, 1993, p.24)

Em "Trem fantasma", a casa natal, que deveria ser um espaço de intimidade e proteção, um celeiro de lembranças futuras associadas à infância e à integridade do eu, apresenta uma atmosfera sombria, é palco de uma encenação que antecipa a expulsão prematura de Matias do reduto familiar e da vida. Os móveis são escuros, as cortinas, de veludo cor de vinho - tonalidade que pode ser associada ao sangue do sacrifício - e a frieza do piso de mármore remete para as lápides dos cemitérios. Assim, está criada uma ambientação de tom sombrio, que se coaduna com o que Lovecraft chama de "literatura do medo" (LOVECRAFT, 2007, p.16), salientando que a "atmosfera é a coisa mais importante, pois o critério final de autenticidade não é a harmonização de um enredo, mas a criação de uma determinada sensação"( LOVECRAFT, 2007, p.17).

Bachelard enfatiza que uma casa é um berço. O berço do menino - casa e o carrinho de bebê, onde ele é colocado para assistir ao espetáculo - é o berço da morte. Numa evocação à tenra idade daquele que deve morrer, dois objetos carrinho de bebê e caixão mortuário - estão associados.

O espetáculo ocorre no dia "três de julho de 1956, às vinte e uma horas" (SCLIAR s.d.,p.79). Impossibilitados de encontrar uma razão que justificasse a 
precisão da data, enveredamos pelo caminho do simbolismo dos números. Dessa forma, constatamos a incidência dos números três e sete. A data escolhida é o dia três de julho, que é o sétimo do ano. No tocante a 1956, a redução numérica resulta no número três $(1+9+5+6=21=2+1=3)$. Além disso, o passeio de Trem Fantasma começa às vinte e uma horas $(21=2+1=3)$. $O$ número três está associado à Trindade, e aqui o interpretamos como símbolo do mistério, daquilo que é inescrutável e que a mente humana não pode apreender. O número sete simboliza um ciclo completo, e, na situação específica do conto, ao ciclo da vida humana juventude, maturidade, velhice e morte - que, no caso de Matias, não irá se completar.

Com as luzes apagadas, o narrador criança, empurrando o carrinho, precipita-se pelos labirintos do solar. No salão estava a mãe de Matias, "disfarçada de bruxa (grossa maquilagem vermelha. Olhos pintados, arregalados. Vestes negras. Sobre o ombro, uma coruja empalhada. Invocava deuses malignos)" (SCLIAR s.d., p.79).

A mãe, como é doadora da vida, insere-se no ciclismo cósmico de vida e morte, daí sua relação com a passagem do tempo e com o aniquilamento da existência, que tem uma conotação negativa, fazendo surgir o reverso da mãe que ama, nutre, protege e agasalha - a Mãe Terrível. Segundo C. G. Jung (2000, p. 92), a bruxa, entre outros, é um símbolo materno nefasto. Essa é a razão de sua presença na alegoria do "Trem Fantasma". Ligada ao vermelho do sangue e ao negro, traz ao ombro uma ave noturna associada ao mau agouro.

Aqui o papel específico da Mãe Terrível é prenunciar a mudança radical que irá ocorrer na vida da família. Ela está, portanto, associada à Roda da Fortuna, representada pelas três moiras - Cloto, a fiandeira; Láquesis, a medidora; e Átropos, a cortadora. Elas eram filhas da Mãe Noite, concebidas sem pai, e, na escuridão de sua gruta, teciam o fio da vida dos homens.

O pai está enforcado no banheiro, "língua de fora, rosto arroxeado" (SCLIAR s.d., p.80). O arquétipo do enforcado está ligado a Prometeu, que se submete ao sacrifício, denotando submissão às leis do inexorável. $O$ irmão de Matias está travestido de esqueleto - "(sobre o tórax magro, costelas pintadas com tintas fosforescentes; nas mãos, uma corrente enferrujada)" (SCLIAR s.d., p. 80). O esqueleto é a própria alegoria da morte, e, dessa forma, remete para Hades, que 
reina no mundo subterrâneo. A corrente enferrujada pode ser entendida não como elo, união, mas como rompimento de vínculos. E as duas irmãs, situadas no gabinete, estão "apunhaladas (facas enterradas nos peitos; rostos lambuzados de sangue de galinha. Uma estertorava)" (SCLIAR s.d.p.80). As facas enterradas nos peitos estão associadas aos vampiros, seres das trevas que somente podem ser aniquilados quando recebem uma estaca no peito.

Essa é uma visão terrorífica da morte no século XX. Philippe Ariès, que apresenta um panorama da morte no Ocidente, declara que é no fim do século XVIII e começo do XIX que a morte realmente se tornou motivo de medo (ARIÈS 2003, p.157). Além disso, chamamos a atenção para o fato de existir, no conto, apenas um terror do desconhecido, nada deixando entrever "a tendência básica da metafísica cuja tarefa principal, desde Platão, é nos lembrar a nossa participação no eterno e nos convidar a superar a contingência e a finitude da vida individual" (DASTUR, 2002, p. 6).

Em "O dia em que matamos James Cagney", repete-se a presença do espetáculo, até mesmo as palavras que anunciam o que se vai assistir, são praticamente as mesmas: em "Trem Fantasma"- "As luzes se apagaram"- (SCLIAR s.d., p.79); em "O dia em que matamos James Cagney" -"Quando as luzes se apagaram" (SCLIAR s.d.,p.81). Mas essa segunda narrativa apresenta uma atmosfera festiva de matinê de domingo, em que travessos garotos - que comem balas café-com-leite, e golpeiam as cabeças uns dos outros com seus gibis - vão assistir a um filme protagonizado por James Cagney (1899-1986), conhecido dançarino e ator norte-americano, que se destacou por desempenhar papéis de gangster e de durão.

Mas aqui Cagney é baixinho e não surrava ninguém, mas é maltratado e finalmente morto por Sam, o bandido, alto e bigodudo, ante os olhos impiedosos dos meninos, que, ansiando por assistir a um filme de mocinho, não lhe perdoam a fraqueza e a covardia, exultando com seu sofrimento e morte.

Se no conto anteriormente estudado não há evento fantástico, mas apenas uma representação alegórica dos fatos, neste se estabelece o inusitado mediante o rompimento dos limites entre realidade e ficção, instalando-se, portanto, a presença do maravilhoso. 
No texto, os meninos, que ansiavam por um filme de aventuras, ficaram decepcionados ao constatar que James Cagney "levava uma surra de quebrar os ossos" (SCLIAR s.d., p.81) cada vez que se encontrava com o bandido. A reação dos meninos ante a violência era de desprezo por aquele a quem chamavam de "fracalhão repelente" (SCLIAR s.d., p.81) e por quem não tinham a menor compaixão, vaiando-o e dizendo palavrões.

O inusitado se estabelece no conto no momento em que o narrador diz: "James Cagney já andava com medo de nós. Deslizava encostado às paredes. Olhava-nos de soslaio" (SCLIAR s.d., p.81). Esse rompimento de fronteiras é reforçado com o estabelecimento da ambiguidade entre o tempo da ficção e aquele que transcorre na sala de projeções: "Três meses depois do início do filme ele leva uma surra formidável de Sam e fica caído no chão, sangrando como um porco" (SCLIAR s.d., p.81). Os garotos sentiam uma revolta tão grande que já não se importariam se ele morresse. Quando um deles notou um crispar de dedos, constatando que estava vivo, resolvem animá-lo: "Achamos que, apesar de tudo, valia a pena trabalhar James Cagney. Iniciamos um aplauso moderado, mas firme" (SCLIAR s.d., p.82). Ele se reanima: "James Cagney levantou-se. Aumentamos um pouco as palmas - não muito, o suficiente para que ele ficasse de pé. Fizemos com que andasse alguns passos" (SCLIAR s.d., p.82). Assim, é estimulado pelos aplausos que a personagem se levanta e se recupera.

A seguir, conduzido pelos meninos, que vaiam, assobiam, batem palmas, e estão convencidos de que o "mocinho" está aprendendo muito bem com eles, Cagney vai à procura do bandido com uma arma, mas é morto por ele. O narrador finaliza a história, declarando que foi o primeiro crime que cometeram, seguindo-se muitos outros posteriormente.

Concluímos afirmando que, nas duas narrativas que tematizam a morte associada à infância utilizando o espetáculo, na primeira, a criança é objeto, e, na segunda, é sujeito de acontecimentos violentos. As duas apresentam um narrador criança - na primeira, o menino de dez anos, amigo de Matias; na segunda, o narrador plural, "nós". Mas, tanto numa como noutra, a linguagem utilizada no texto não é propriamente a de uma criança, fazendo-nos acreditar que entre a ocorrência dos fatos e o momento da escrita tenha transcorrido algum tempo. Corroboram nossa constatação as seguintes afirmativas: "Matias morreu algumas semanas 
depois. Não me lembro de ter andado de Trem Fantasma desde então" (SCLIAR s.d., p.80). "Cometemos muitos outros [crimes] depois" (SCLIAR s.d., p.83).

Mas os contos se afastam no tocante à atmosfera criada em decorrência daquilo a que se propõe. Em "Trem Fantasma” estão presentes os matizes góticos para representar o "medo cósmico" e primevo ante o desconhecido, de que fala Lovecraft. Em "O dia em que matamos James Cagney", a morte está associada à sociedade de consumo e aos mitos modernos que alimentam a violência. $O$ mito que, como declara Mircea Eliade, persiste na atualidade, é mostrado aqui no seu reverso, pois ele é desmitificado, quando crianças visualizam o herói como um antiherói, massacrado e morto por um bandido chamado Sam. Acreditamos que o nome seja uma alusão a Tio Sam, pois, intoxicados pelas películas americanas de violência, os garotos cometem o primeiro crime fictício, transformando-se em criminosos em potencial.

Abstract: This study aims to study the strangeness caused by death that, in two short stories by the Brazilian writer Moacyr Scliar, is associated with horror and violence related to the child. Our analysis will focus on the narratives "Ghost Train" and "The Day We Kill James Cagney," both published in the collection The Carnival of Animals, originally published in 1968.

Keywords: Moacyr Scliar. Brazilian tales. Fantastic Narrative. Childhood.

\section{Referências}

ARIÈS, Philippe. História da morte no Ocidente. Trad. Priscila Viana de Siqueira. Rio de Janeiro: Ediouro, 2003.

BACHELARD, Gaston. A poética do espaço. Trad. Antonio de Pádua Danesi. São Paulo: Martins Fontes, 1993.

DASTUR, Françoise. A morte: ensaio sobre a finitude.Trad. Maria Tereza Pontes. Rio de Janeiro: DIFEL, 2002.

ELIADE, Mircea. Mito e realidade. Trad. Pola Civelli. São Paulo: Perspectiva, 1972.

HANSEN, João Adolfo. Alegoria: Construção e interpretação da metáfora. São Paulo: Atual, 1986.

JUNG, C.G. Os arquétipos e o inconsciente coletivo. Tradução Maria Luíza Appy, Dora Mariana R. Ferreira da Silva.Petrópolis, RJ: Vozes, 2000.

LOVECRAFT, H. P. O horror sobrenatural em literatura. Trad. Celso M. Parcionik. São Paulo: lluminuras, 2007. 
SCLIAR, Moacyr. O carnaval dos animais. Rio de Janeiro: Ediouro, S.d.

TODOROV, Tzvetan. Introdução à literatura fantástica. Tradução de Maria Clara Correa Castello. São Paulo: Perspectiva, 1975.

Data da Submissão: 06/05/2019

Data da Aprovação: 18/07/2019

Revista de Letras JUÇARA, Caxias - Maranhão, v. 03, n. 01, p. 278 - 287, ago. 2019 | 287 